Research Article

\title{
Impact-Time-Control Guidance Law for Missile with Time-Varying Velocity
}

\author{
Jun Zhou, Yang Wang, and Bin Zhao \\ Institute of Precision Guidance and Control, Northwestern Polytechnical University, Xian 710072, China \\ Correspondence should be addressed to Yang Wang; 2013100280@mail.nwpu.edu.cn
}

Received 25 January 2016; Accepted 5 June 2016

Academic Editor: Andrzej Swierniak

Copyright (C) 2016 Jun Zhou et al. This is an open access article distributed under the Creative Commons Attribution License, which permits unrestricted use, distribution, and reproduction in any medium, provided the original work is properly cited.

\begin{abstract}
The problem of impact-time-control guidance (ITCG) for the homing missile with time-varying velocity is addressed. First, a novel ITCG law is proposed based on the integral sliding mode control (ISMC) method. Then, a salvo attack algorithm is designed based on the proposed guidance law. The performances of the conventional ITCG laws strongly depend on the accuracy of the estimated time-to-go (TTG). However, the accurate estimated TTG can be obtained only if the missile velocity is constant. The conventional ITCG laws were designed under the assumption that the missile velocity is constant. The most attractive feature of this work is that the newly proposed ITCG law relaxes the constant velocity assumption, which only needs the variation range of the missile velocity. Finally, the numerical simulation demonstrates the effectiveness of the proposed method.
\end{abstract}

\section{Introduction}

Proportional navigation guidance law (PNGL) [1-4] has been widely used in the area of homing guidance, which can achieve excellent performance in the presence of a nonmaneuvering target. However, in recent years, with the development of defense systems such as space defense antimissile system [5], electronic countermeasure system (ECMS) [6], and close-in weapon system (CIWS) [7], the survivability of attack missile with conventional guidance scheme has been intimidated. Fortunately, most defense systems have "one-toone" feature; thus the salvo attack of multiple missiles can be one of the most effective countermeasures for missiles against the threats of defense systems. The salvo attack can be realized if all missiles hit the target simultaneously; this is called impact-time-control guidance (ITCG).

In 2006, Jeon et al. [8] first proposed an ITCG law to realize the salvo attack. The solution is a combination of the PNGL and the feedback of the impact time error. In [9], a cooperative-proportional navigation guidance (CPNG) law was designed to realize the salvo attack by decreasing the time-to-go (TTG) variance of missiles. In [10], a bias proportional navigation guidance (BPNG) law was developed, in which the desired impact time and angle were achieved simultaneously. In [11], the authors proposed an optimal guidance law for controlling the impact time and angle. In [12], an ITCG law based on a two-step control strategy was proposed. In [13], the authors proposed a polynomial guidance law to control the impact time and angle.

Actually, the above-mentioned ITCG laws in [8-13] were designed based on linearized-engagement-dynamics. However, the linearized-engagement-dynamic-based method can achieve high precision only if the missile's flight-path angle is small. It is well known that the sliding mode control (SMC) method is powerful in controlling nonlinear system [14-17]. So far, some SMC-based ITCG laws have been developed in [18-20]. And they were derived based on the nonlinear engagement dynamics. In [18], a guidance law based on the second-order SMC method and the backstepping scheme was developed. In order to satisfy the impact time constraint, one coefficient of the guidance law was searched for by using the off-line simplex algorithm. In [19], a SMC-based guidance law was developed to meet the requirement of ITCG, in which the sliding mode was defined as the combination of the line-ofsight (LOS) angle rate and the impact time error. However, if the initial LOS angle is zero, the guidance law proposed in [19] will generate zero-acceleration command during the whole guidance process. To overcome this problem, in 2015, 
Cho et al. [20] proposed an ITCG law based on a nonsingular sliding mode. Compared with the sliding mode in [19], the sliding mode in [20] was defined as only the impact time error.

Note that the aforementioned ITCG laws in [8-13, 18-20] all need the TTG. However, the TTG cannot be measured directly. To overcome this problem, $[8-13,18-20]$ all design estimation algorithm to estimate the TTG. These estimation results in $[8-13,18-20]$ are obtained under the assumption that the missile velocity is invariant. However, the assumption is too restrictive for many cases. In practical missile systems, the missile velocity is affected inevitably by various forces such as the driving force of engine and the aerodynamic forces. When the constant velocity assumption is invalid, the estimation error of TTG may be large. Thus, these guidance laws in $[8-13,18-20]$ may not work well in practical situations.

In this paper, a novel ITCG law is proposed for missile with time-varying velocity, based on integral sliding mode control (ISMC). The main contributions of this paper are the following:

(1) As far as we know, the ITCG law for the missile with time-varying velocity is achieved for the first time. Compared with the conventional ITCG laws in [8$13,18-20]$, the constant velocity assumption is relaxed in this paper. In other words, the proposed law is more practical than the conventional ITCG laws.

(2) The proposed guidance law is derived based on the nonlinear engagement dynamic rather than the linearized dynamics used in [8-13].

The remaining parts of this paper are as follows. In Section 2, the problems of existing ITCG laws are formulated. The main results are presented in Section 3. In Section 3, an ITCG law based on ISMC method is proposed and the permissible set of the desired impact times is discussed. Section 4 shows a salvo attack algorithm based on the proposed guidance law. In Section 5, the numerical simulations verify the effectiveness of the proposed method in comparison with the methods presented in $[8,20]$. In Section 6, the conclusions of the whole paper are presented.

Notations. The following notations will be used in this paper. $t$ denotes the elapsed time after launching the missile, $x_{0}$ denotes $x$ at initial time $t_{0}$, and $x\left(t_{k}\right)$ denotes $x$ at time $t_{k}$.

\section{Problem Formulation}

As shown in Figure 1, $O x$ represents the horizontal direction, $O y$ represents the longitudinal direction, $T$ represents the stationary target, $M$ represents the missile, $\lambda$ represents the LOS angle, $R$ represents the relative distance between the missile and the target, $\gamma$ represents the heading angle, $a_{M}$ represents the missile acceleration, and $V$ represents the missile velocity. From Figure 1, the following equalities can be established [20]:

$$
\begin{aligned}
& \dot{x}=V \cos \gamma, \\
& \dot{y}=V \sin \gamma,
\end{aligned}
$$

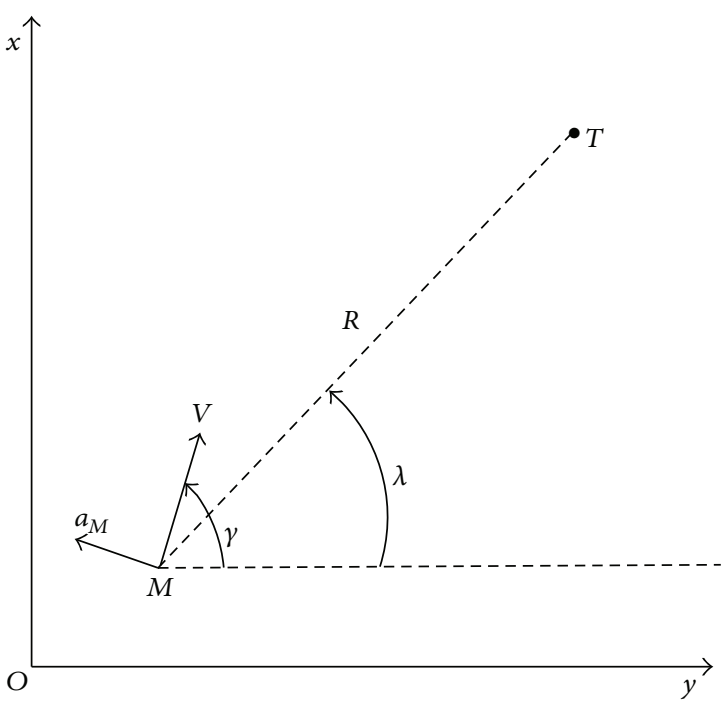

FIGURE 1: Missile-target engagement geometry.

where $(x, y)$ are the coordinates of missile. The equations for relative motion can be expressed as [20]

$$
\begin{aligned}
\dot{R} & =-V \cos (\lambda-\gamma)=-V \cos \phi, \\
R \dot{\lambda} & =-V \sin (\lambda-\gamma)=-V \sin \phi, \\
a_{M} & =V \dot{\gamma}, \\
\dot{V} & =\frac{1}{2} C_{x} \rho V^{2} \frac{S_{M}}{m},
\end{aligned}
$$

where $C_{x}$ denotes the aerodynamic coefficients, $\rho$ denotes the air density, $S_{M}$ denotes the reference area, $m$ denotes the missile mass, and $a_{M}$ denotes the lateral acceleration. It is assumed that air resistance plays a major role in the change of the missile velocity; thus we have

$$
C_{x}<0 .
$$

Note that if condition (4) is satisfied, then the objective of ITCG is realized $[8-13,18-20]$ :

$$
t_{f}=t_{f}^{d}
$$

where $t_{f}$ denotes the impact time and $t_{f}^{d}$ denotes the desired impact time. $t_{f}$ can be rewritten as

$$
t_{f}=t+t_{\mathrm{go}}
$$

where $t$ is the elapsed time after launching the missile and $t_{\mathrm{go}}$ is the time-to-go (TTG).

Combining (4) with (5), condition (4) is equivalent to the following condition:

$$
t_{f}^{d}=t+t_{\mathrm{go}} .
$$


In order to satisfy (6), the conventional ITCG laws in [8-13, 18-20] need $t_{\text {go }}$. However, $t_{\text {go }}$ can not be measured directly. These literatures design estimation algorithm to estimate the TTG. The performances of these ITCG laws strongly depend on the accuracy of the estimated TTG.

The length of the trajectory of missile, $S$, is given by

$$
S=\int_{t_{0}}^{t_{f}} V d t=\int_{x_{0}}^{x\left(t_{f}\right)} \sqrt{1+\left(\frac{d y}{d x}\right)^{2}} d x .
$$

If $V$ is constant $(\dot{V}=0)$, then we have

$$
t_{f}=\frac{1}{V} \int_{x_{0}}^{x\left(t_{f}\right)} \sqrt{1+\left(\frac{d y}{d x}\right)^{2}} d x+t_{0}
$$

Combining (5) with (8), we have

$$
t_{\mathrm{go}}=\frac{1}{V} \int_{x_{0}}^{x\left(t_{f}\right)} \sqrt{1+\left(\frac{d y}{d x}\right)^{2}} d x+t_{0}-t .
$$

Based on (9), the estimated TTG $\widehat{t}_{\text {go }}$ is obtained in $[8-13,18-$ 20]. For example, in [8], the estimated TTG is

$$
\widehat{t}_{\mathrm{go}}=\frac{R}{V}\left(1+\frac{(\gamma-\lambda)^{2}}{10}\right) .
$$

In [9], the estimated TTG is

$$
\widehat{t}_{\mathrm{go}}=\frac{R}{V}\left(1+\frac{(\gamma-\lambda)^{2}}{2(2 N-1)}\right),
$$

where $N$ is a constant parameter.

However, if $V$ is time-varying, (8) cannot be derived from (7). In other word, the estimation error of TTG may be very large if we still use the estimation methods in $[8-13,18-$ 20]. And the requirement of the ITCG cannot be satisfied with their guidance laws (in Section 5 of this paper, the simulation result also demonstrates that the performance of existing ITCG laws is poor when the missile velocity is timevarying). This motivates the research topic of this paper, that is, designing a new ITCG law for missile with time-varying velocity to satisfy condition (4).

The following assumptions should be assumed to be valid throughout this paper:

(A1) Missile velocity $V$ satisfies $V_{\min } \leq V \leq V_{\max }$, where $V_{\min }$ and $V_{\max }$ are the known constants.

(A2) $\dot{V}$ is available (see [21-23]).

Assumption (A1) implies that we only need the bound of the time-varying velocity. Obviously, assumption (A1) is a relaxed version of the constant velocity assumption used in [8-13, 18-20]. Because $\dot{V}$ can be measured by accelerometer, assumption (A2) is a commonly used assumption for the design of guidance law (see [21-23]).

\section{New Impact-Time-Control Guidance Law Based on ISMC}

3.1. Design of ITCG Law. Condition (4) is equivalent to the following conditions:

$$
\begin{aligned}
R(t) & >0, \quad \forall t_{0} \leq t<t_{f}^{d}, \\
R\left(t_{f}^{d}\right) & =0 .
\end{aligned}
$$

Conditions (12) mean that the missile can attack the target only if $t=t_{f}^{d}$. In this section, a novel ITCG law is developed to satisfy (12).

A state variable $z_{1}$ is defined as

$$
z_{1}=R-V_{\min }\left(t_{f}^{d}-t\right)
$$

Differentiating (13) gives

$$
\dot{z}_{1}=\dot{R}+V_{\text {min }}
$$

Let $\dot{z}_{1}=z_{2}$, and the guidance system (2) can be rewritten as

$$
\begin{aligned}
& \dot{z}_{1}=z_{2}, \\
& \dot{z}_{2}=f(z)+g(z) u, \\
& \dot{V}=\frac{1}{2} C_{x} \rho V^{2} \frac{S_{M}}{m},
\end{aligned}
$$

where $u=a_{M}, f(z)=-\dot{V} \cos (\lambda-\gamma)+V \sin (\lambda-\gamma) \dot{\lambda}$ and $g(z)=-\sin (\lambda-\gamma)$.

A novel integral sliding mode (ISM) is constructed as

$$
s_{\mathrm{ISM}}=z_{2}-z_{2}\left(t_{0}\right)+\int_{t_{0}}^{t}\left(\frac{b\left(t_{f}^{d}-t\right) z_{2}+c z_{1}}{a\left(t_{f}^{d}-t\right)^{2}}\right) d \tau
$$

where $a, b$, and $c$ are the guidance parameters, which are all constants. Then, using the following guidance law:

$$
\begin{aligned}
u= & -g^{-1}(z) \\
& \left(f(z)+\frac{b\left(t_{f}^{d}-t\right) z_{2}+c z_{1}}{a\left(t_{f}^{d}-t\right)^{2}}+\beta \operatorname{sgn}\left(s_{\text {ISM }}\right)\right),
\end{aligned}
$$

where $\beta$ is a small positive constant and $\operatorname{sgn}(\cdot)$ denotes the signum function, we have the following results. 
Theorem 1. Consider system (15) with the guidance law (17), provided that $q_{1}$ and $q_{2}$ are the solutions to the equation $a q^{2}-$ $(a+b) q+c=0$, where $a, b$, and $c$ are the guidance parameters in (17). If $t_{f}^{d}$ satisfies

$$
\begin{aligned}
t_{0} & +\frac{R_{0} q_{2}}{-\dot{R}_{0}-\left(1-q_{2}\right) V_{\text {min }}}<t_{f}^{d} \\
& <t_{0}+\frac{R_{0} q_{1}}{-\dot{R}_{0}-\left(1-q_{1}\right) V_{\text {min }}}, \text { if } q_{2}>q_{1}, \\
t_{0} & +\frac{R_{0} q_{1}}{-\dot{R}_{0}-\left(1-q_{1}\right) V_{\text {min }}}<t_{f}^{d} \\
& <t_{0}+\frac{R_{0} q_{2}}{-\dot{R}_{0}-\left(1-q_{2}\right) V_{\text {min }}}, \text { if } q_{1}>q_{2},
\end{aligned}
$$

$q_{1} \geq 2, q_{2} \geq 2, q_{1} \neq q_{2}$, and $\left|V_{0} \cos \left(\lambda_{0}-\gamma_{0}\right) / V_{\min }\right|<1$, then the following conditions will be satisfied:

$$
\begin{aligned}
R(t) & >0, \quad \forall t_{0} \leq t<t_{f}^{d}, \\
R\left(t_{f}^{d}\right) & =0 .
\end{aligned}
$$

Proof. Differentiating (16) with respect to time yields

$$
\dot{s}_{\mathrm{ISM}}=\dot{z}_{2}+\frac{b\left(t_{f}^{d}-t\right) z_{2}+c z_{1}}{a\left(t_{f}^{d}-t\right)^{2}} .
$$

Combining (15) with (20), we have

$$
\dot{s}_{\text {ISM }}=f(z)+g(z) u+\frac{b\left(t_{f}^{d}-t\right) z_{2}+c z_{1}}{a\left(t_{f}^{d}-t\right)^{2}} .
$$

Construct a Lyapunov function $V_{1}$ as

$$
V_{1}=\frac{1}{2} s_{\text {ISM }}^{2} .
$$

Differentiating (22) and then using (21) and (17) yield

$$
\begin{aligned}
\dot{V}_{1} & =s_{\mathrm{ISM}} \dot{s}_{\mathrm{ISM}} \\
& =s_{\mathrm{ISM}}\left(f(z)+g(z) u+\frac{b\left(t_{f}^{d}-t\right) z_{2}+c z_{1}}{a\left(t_{f}^{d}-t\right)^{2}}\right) \\
& =-s_{\mathrm{ISM}}\left(\beta \operatorname{sgn}\left(s_{\mathrm{ISM}}\right)\right)<0, \text { when } s_{\mathrm{ISM}} \neq 0 .
\end{aligned}
$$

Note that $s_{\text {ISM }}\left(t_{0}\right)=0$, and one can imply that

$$
s_{\text {ISM }}(t)=0, \quad \forall t_{0} \leq t \leq t_{f}^{d} .
$$

As $s_{\text {ISM }}(t)$ remains as zero, we get

$$
\dot{s}_{\text {ISM }}(t)=0, \quad \forall t_{0} \leq t \leq t_{f}^{d} .
$$

The following equation can be obtained by combining (20) with (25):

$$
\begin{aligned}
& a\left(t_{f}^{d}-t\right)^{2} \ddot{z}_{1}+b\left(t_{f}^{d}-t\right) \dot{z}_{1}+c z_{1}=0, \\
& \forall t_{0} \leq t \leq t_{f}^{d} .
\end{aligned}
$$

Provided that $q_{1}$ and $q_{2}$ are the solutions to the equation $a q^{2}-$ $(a+b) q+c=0$, if $q_{1} \neq q_{2}, q_{1} \geq 2$, and $q_{2} \geq 2$, the solutions to the differential equation (26) can be easily obtained as

$$
\begin{aligned}
& z_{1}=c_{1}\left(t_{f}^{d}-t\right)^{q_{1}}+c_{2}\left(t_{f}^{d}-t\right)^{q_{2}}, \quad \forall t_{0} \leq t \leq t_{f}^{d}, \\
& \dot{z}_{1}=-c_{1} q_{1}\left(t_{f}^{d}-t\right)^{q_{1}-1}-c_{2} q_{2}\left(t_{f}^{d}-t\right)^{q_{2}-1}, \\
& \forall t_{0} \leq t \leq t_{f}^{d},
\end{aligned}
$$

where $c_{1}$ and $c_{2}$ are constant.

Substituting (13) into (27) and substituting (14) into (28) yield

$$
\begin{aligned}
& R-V_{\min }\left(t_{f}^{d}-t\right)= c_{1}\left(t_{f}^{d}-t\right)^{q_{1}}+c_{2}\left(t_{f}^{d}-t\right)^{q_{2}}, \\
& \forall t_{0} \leq t \leq t_{f}^{d}, \\
& \dot{R}+V_{\min }=-c_{1} q_{1}\left(t_{f}^{d}-t\right)^{q_{1}-1} \\
&-c_{2} q_{2}\left(t_{f}^{d}-t\right)^{q_{2}-1}, \\
& \forall t_{0} \leq t \leq t_{f}^{d} .
\end{aligned}
$$

Substituting the initial values $R_{0}$ and $\dot{R}_{0}$ into (29) and (30), we get

$$
\begin{array}{r}
R_{0}-V_{\min }\left(t_{f}^{d}-t_{0}\right)=c_{1}\left(t_{f}^{d}-t_{0}\right)^{q_{1}}+c_{2}\left(t_{f}^{d}-t_{0}\right)^{q_{2}}, \\
\forall t_{0} \leq t \leq t_{f}^{d}, \\
\left(\dot{R}_{0}+V_{\min }\right)\left(t_{f}^{d}-t_{0}\right)=-c_{1} q_{1}\left(t_{f}^{d}-t_{0}\right)^{q_{1}} \\
-c_{2} q_{2}\left(t_{f}^{d}-t_{0}\right)^{q_{2}}, \\
\forall t_{0} \leq t \leq t_{f}^{d} .
\end{array}
$$

From (31), we have

$$
\begin{gathered}
c_{1}=\frac{\left(\dot{R}_{0}+V_{\min }\left(1-q_{2}\right)\right)\left(t_{f}^{d}-t_{0}\right)+q_{2} R_{0}}{\left(q_{2}-q_{1}\right)\left(t_{f}^{d}-t_{0}\right)^{q_{1}}}, \\
c_{2}=\frac{\left(-\dot{R}_{0}-V_{\min }\left(1-q_{1}\right)\right)\left(t_{f}^{d}-t_{0}\right)-q_{1} R_{0}}{\left(q_{2}-q_{1}\right)\left(t_{f}^{d}-t_{0}\right)^{q_{2}}} .
\end{gathered}
$$

According to (18), $\left|V_{0} \cos \left(\lambda_{0}-\gamma_{0}\right) / V_{\min }\right|<1, q_{1} \geq 2$, and $q_{2} \geq 2$, we have

$$
\begin{aligned}
& c_{1}<0, \\
& c_{2}<0 .
\end{aligned}
$$


From (32), (33), and $t_{f}^{d}-t_{0}>0$, one can imply that

$$
\begin{gathered}
\frac{\left(\dot{R}_{0}+V_{\min }\left(1-q_{2}\right)\right)\left(t_{f}^{d}-t_{0}\right)+q_{2} R_{0}}{\left(q_{2}-q_{1}\right)}<0, \\
\frac{\left(-\dot{R}_{0}-V_{\min }\left(1-q_{1}\right)\right)\left(t_{f}^{d}-t_{0}\right)-q_{1} R_{0}}{\left(q_{2}-q_{1}\right)}<0 .
\end{gathered}
$$

Substituting (32) into (29), we have

$$
\begin{aligned}
R- & V_{\min }\left(t_{f}^{d}-t\right) \\
& =\frac{\left(\dot{R}_{0}+V_{\min }\left(1-q_{2}\right)\right)\left(t_{f}^{d}-t_{0}\right)+q_{2} R_{0}}{\left(q_{2}-q_{1}\right)} \\
& \cdot \frac{\left(t_{f}^{d}-t\right)^{q_{1}}}{\left(t_{f}^{d}-t_{0}\right)^{q_{1}}} \\
& +\frac{\left(-\dot{R}_{0}-V_{\min }\left(1-q_{1}\right)\right)\left(t_{f}^{d}-t_{0}\right)-q_{1} R_{0}}{\left(q_{2}-q_{1}\right)} \\
& \cdot \frac{\left(t_{f}^{d}-t\right)^{q_{2}}}{\left(t_{f}^{d}-t_{0}\right)^{q_{2}}}, \quad \forall t_{0} \leq t \leq t_{f}^{d} .
\end{aligned}
$$

Considering (34), $0 \leq\left(t_{f}^{d}-t\right) /\left(t_{f}^{d}-t_{0}\right) \leq 1, q_{1} \geq 2$, and $q_{2} \geq 2$, we get (36) from (35). Consider

$$
\begin{aligned}
& R- V_{\min }\left(t_{f}^{d}-t\right) \\
& \geq \frac{\left(\dot{R}_{0}+\left(1-q_{2}\right) V_{\min }\right)\left(t_{f}^{d}-t_{0}\right)+q_{2} R_{0}}{\left(q_{2}-q_{1}\right)} \frac{\left(t_{f}^{d}-t\right)}{\left(t_{f}^{d}-t_{0}\right)} \\
&+\frac{\left(-\dot{R}_{0}-\left(1-q_{1}\right) V_{\min }\right)\left(t_{f}^{d}-t_{0}\right)-q_{1} R_{0}}{\left(q_{2}-q_{1}\right)} \\
& \frac{\left(t_{f}^{d}-t\right)}{\left(t_{f}^{d}-t_{0}\right)}=R_{0} \frac{\left(t_{f}^{d}-t\right)}{\left(t_{f}^{d}-t_{0}\right)}-V_{\min }\left(t_{f}^{d}-t\right), \\
& \quad \forall t_{0} \leq t \leq t_{f}^{d} .
\end{aligned}
$$

Then, we get

$$
R \geq R_{0} \frac{\left(t_{f}^{d}-t\right)}{\left(t_{f}^{d}-t_{0}\right)}>0, \quad \forall t_{0} \leq t<t_{f}^{d}
$$

Moreover, according to (29), we get

$$
R\left(t_{f}^{d}\right)=0
$$

The proof is finished.
Remark 2. From Theorem 1, it is clear that the proposed guidance law (17) can guarantee each missile attacks the target only when $t=t_{f}^{d}$.

Remark 3. Equation (17) shows that the control law contains $\left(t_{f}^{d}-t\right)$ in the denominator, which may bring the singularity when $t=t_{f}^{d}$. Fortunately, the singularity can be eliminated; combining (27) with (28) yields

$$
\begin{array}{r}
\frac{b\left(t_{f}^{d}-t\right) \dot{z}_{1}+c z_{1}}{a\left(t_{f}^{d}-t\right)^{2}}=\left(\frac{c_{1} c}{a}-\frac{c_{1} q_{1} b}{a}\right)\left(t_{f}^{d}-t\right)^{q_{1}-2} \\
+\left(\frac{c_{2} c}{a}-\frac{c_{2} q_{2} b}{a}\right)\left(t_{f}^{d}-t\right)^{q_{2}-2}, \\
\forall t_{0} \leq t \leq t_{f}^{d} .
\end{array}
$$

From (39), we can know that the singularity brought by $\left(t_{f}^{d}-t\right)$ is eliminated as long as $q_{1} \geq 2$ and $q_{2} \geq 2$.

3.2. Nonsingular Impact-Time-Control Guidance Law. If $g(z)=0$, (17) shows that the guidance command $u \rightarrow \infty$, which means it is impossible to realize the guidance law. In what follows, Theorem 4 shows the condition which can ensure $g(z) \neq 0$ during the guidance process.

Theorem 4. Consider system (15) with the guidance law (17). Provided that $q_{1}$ and $q_{2}$ are the solutions to the equation $a q^{2}-$ $(a+b) q+c=0$, where $a, b$, and $c$ are the parameters in (17), if $t_{f}^{d}$ satisfies (18), $q_{1} \geq 2, q_{2} \geq 2, q_{1} \neq q_{2}, \sin \left(\lambda_{0}-\gamma_{0}\right) \neq 0$, and $\left|V_{0} \cos \left(\lambda_{0}-\gamma_{0}\right) / V_{\text {min }}\right|<1-\psi<1$, then $g(z)$ satisfies the following condition:

$$
|g(z)| \geq \bar{\theta}>0, \quad \forall t_{0} \leq t \leq t_{f}^{d}-\varepsilon,
$$

where $\varepsilon$ is a sufficiently small time and

$$
\begin{aligned}
& \bar{\theta}=\min \left\{\sqrt{1-\bar{\psi}},\left|\sin \left(\lambda_{0}-\gamma_{0}\right)\right|\right\}, \\
& \bar{\psi}=\max \left\{\left(\frac{V_{\text {min }}}{\bar{V}}\right)^{2},(-1+\psi)^{2}\right\},
\end{aligned}
$$

where $\bar{V}$ is the value of $V$ at time $t=t_{f}^{d}-\varepsilon$.

Proof. From the demonstration of Theorem 4, we known that the guidance law (17) can ensure the state variables of system (15) satisfy the following equations:

$$
\begin{aligned}
& z_{1}=c_{1}\left(t_{f}^{d}-t\right)^{q_{1}}+c_{2}\left(t_{f}^{d}-t\right)^{q_{2}}, \quad \forall t_{0} \leq t \leq t_{f}^{d}, \\
& \dot{z}_{1}=-c_{1} q_{1}\left(t_{f}^{d}-t\right)^{q_{1}-1}-c_{2} q_{2}\left(t_{f}^{d}-t\right)^{q_{2}-1}, \\
& \forall t_{0} \leq t \leq t_{f}^{d},
\end{aligned}
$$

where $c_{1}$ and $c_{2}$ are constants and $q_{1}$ and $q_{2}$ are the solutions to the equation $a q^{2}-(a+b) q+c=0$. 

yield

Substituting (13) into (43) and substituting (14) into (44)

$$
\begin{aligned}
& R-V_{\min }\left(t_{f}^{d}-t\right)= c_{1}\left(t_{f}^{d}-t\right)^{q_{1}}+c_{2}\left(t_{f}^{d}-t\right)^{q_{2}}, \\
& \forall t_{0} \leq t \leq t_{f}^{d}, \\
& \dot{R}+V_{\min }=-c_{1} q_{1}\left(t_{f}^{d}-t\right)^{q_{1}-1} \\
&-c_{2} q_{2}\left(t_{f}^{d}-t\right)^{q_{2}-1}, \\
& \forall t_{0} \leq t \leq t_{f}^{d} .
\end{aligned}
$$

According to (18), $q_{1} \geq 2$, and $q_{2} \geq 2$, we can get the following results from the demonstration of Theorem 4 :

$$
\begin{aligned}
& c_{1}<0, \\
& c_{2}<0 .
\end{aligned}
$$

Combining (47) with (46) yields

$$
\dot{R}+V_{\min }>0, \quad \forall t_{0} \leq t<t_{f}^{d} .
$$

Substituting (2) into (48) yields

$$
\cos (\lambda-\gamma)<\frac{V_{\min }}{V}, \quad \forall t_{0} \leq t<t_{f}^{d} .
$$

Differentiating (44) gives

$$
\begin{aligned}
\ddot{z}_{1}= & c_{1} q_{1}\left(q_{1}-1\right)\left(t_{f}^{d}-t\right)^{\left(q_{1}-2\right)} \\
& +c_{2} q_{2}\left(q_{2}-1\right)\left(t_{f}^{d}-t\right)^{\left(q_{2}-2\right)}, \quad \forall t_{0} \leq t<t_{f}^{d} .
\end{aligned}
$$

Then, considering $q_{1} \geq 2, q_{2} \geq 2, c_{1}<0$, and $c_{2}<0$, we have

$$
\ddot{z}_{1}<0, \quad \forall t_{0} \leq t<t_{f}^{d} .
$$

Equation (51) means that $\dot{z}_{1}$ reduces monotonically with increasing $t$, and we get

$$
\dot{z}_{1}<\dot{z}_{1}\left(t_{0}\right), \quad \forall t_{0}<t<t_{f}^{d} .
$$

From (52), we get

$$
\cos (\lambda-\gamma)>\frac{V_{0} \cos \left(\lambda_{0}-\gamma_{0}\right)}{V}, \quad \forall t_{0}<t<t_{f}^{d} .
$$

Combining (49) and (53) yields

$$
\begin{aligned}
& \frac{V_{0} \cos \left(\lambda_{0}-\gamma_{0}\right)}{V}<\cos (\lambda-\gamma)<\frac{V_{\min }}{V}, \\
& \forall t_{0}<t<t_{f}^{d} .
\end{aligned}
$$

From (3), it can be known that $\dot{V}<0$. Then, we have

$$
\frac{V_{\min }}{V} \leq \frac{V_{\min }}{\bar{V}}<1, \quad \forall t_{0}<t \leq t_{f}^{d}-\varepsilon,
$$

where $\bar{V}$ is the value of $V$ at time $t=t_{f}^{d}-\varepsilon$.
Since $V_{\min } / V \leq V_{\min } / \bar{V}<1$ and $V_{0} \cos \left(\lambda_{0}-\gamma_{0}\right) / V \geq$ $-\left|V_{0} \cos \left(\lambda_{0}-\gamma_{0}\right) / V_{\min }\right|>-1+\psi>-1$, we have

$$
-1+\psi<\cos (\lambda-\gamma) \leq \frac{V_{\min }}{\bar{V}}, \quad \forall t_{0}<t \leq t_{f}^{d}-\varepsilon .
$$

Let $\bar{\psi}=\max \left\{\left(V_{\min } / \bar{V}\right)^{2},(-1+\psi)^{2}\right\}$, then we have

$$
\cos ^{2}(\lambda-\gamma) \leq \bar{\psi}, \quad \forall t_{0}<t \leq t_{f}^{d}-\varepsilon .
$$

It is clear that $0<\bar{\psi}<1$. Since $|\sin (\lambda-\gamma)|=$ $\sqrt{1-\cos ^{2}(\lambda-\gamma)}$, we have

$$
|\sin (\lambda-\gamma)| \geq \sqrt{1-\bar{\psi}}, \quad \forall t_{0}<t \leq t_{f}^{d}-\varepsilon .
$$

Let $\bar{\theta}=\min \left\{\sqrt{1-\bar{\psi}},\left|\sin \left(\lambda_{0}-\gamma_{0}\right)\right|\right\}$, we have

$$
|\sin (\lambda-\gamma)| \geq \bar{\theta}, \quad \forall t_{0} \leq t \leq t_{f}^{d}-\varepsilon .
$$

Since $\left|\sin \left(\lambda_{0}-\gamma_{0}\right)\right|>0$ and $\sqrt{1-\bar{\psi}}>0$, we have

$$
|\sin (\lambda-\gamma)| \geq \bar{\theta}>0, \quad \forall t_{0} \leq t \leq t_{f}^{d}-\varepsilon .
$$

Then, we have

$$
|g(z)| \geq \bar{\theta}>0, \quad \forall t_{0} \leq t \leq t_{f}^{d}-\varepsilon,
$$

where $\varepsilon$ is a sufficiently small time. The proof is finished.

Remark 5. In the practical engineering, the available missile acceleration is bounded:

$$
|u| \leq u_{\max }
$$

where $u_{\max }$ is the maximum available acceleration of missile and is determined by the performance of missile. Let $\bar{u}=$ $-g^{-1}(z)\left(f(z)+\left(b\left(t_{f}^{d}-t\right) z_{2}+c z_{1}\right) / a\left(t_{f}^{d}-t\right)^{2}+\beta \operatorname{sgn}\left(s_{\text {ISM }}\right)\right)$. To satisfy (62) in the practical engineering, the guidance law (17) must be modified as

$$
u= \begin{cases}u_{\max } ; & \text { if } \bar{u}>u_{\max } \\ \bar{u} ; & \text { if }|\bar{u}| \leq u_{\max } \\ -u_{\max } ; & \text { if } \bar{u}<-u_{\max } .\end{cases}
$$

In the most ideal case $\left(u_{\max }=\infty\right)$, we can expect the relative distance $R\left(t_{f}^{d}\right)=0$. However, $u_{\max }$ is bounded in engineering. Fortunately, from [8], it can be known that the objective of ITCG can be realized if the impact time error is smaller than $0.1 \mathrm{~s}$. Thus, if the following conditions (63), (64), and (65) can be satisfied simultaneously, the objective of ITCG also can be obtained:

$$
\begin{aligned}
R & >0, \quad \forall t_{0} \leq t \leq t_{f}^{d}-\varepsilon, \\
\left|R\left(t_{f}^{d}-\varepsilon\right)\right| & \leq R_{\text {set }}, \\
|\bar{u}| & \leq u_{\max }, \quad \forall t_{0} \leq t \leq t_{f}^{d}-\varepsilon,
\end{aligned}
$$


where $\varepsilon$ is a sufficiently small time and $\varepsilon<0.1 . R_{\text {set }}$ is a small distance that can guarantee the precision of attack (e.g., if the target is ship, $R_{\text {set }}=1 \mathrm{~m}$ can guarantee the precision of attack).

From (2), we have

$$
\dot{\lambda}=\frac{-V \sin (\lambda-\gamma)}{R}=\frac{V}{R} g(z) .
$$

$$
\begin{aligned}
\bar{u} & =-g^{-1}(z)\left(f(z)+\left(\frac{c_{1} c}{a}-\frac{c_{1} q_{1} b}{a}\right)\left(t_{f}^{d}-t\right)^{q_{1}-2}+\left(\frac{c_{2} c}{a}-\frac{c_{2} q_{2} b}{a}\right)\left(t_{f}^{d}-t\right)^{q_{2}-2}+\beta \operatorname{sgn}\left(s_{\text {ISM }}\right)\right)=-g^{-1}(z) \\
& \cdot\left(-\dot{V} \cos (\lambda-\gamma)+\frac{V^{2} \sin (\lambda-\gamma) g(z)}{R}+\left(\frac{c_{1} c}{a}-\frac{c_{1} q_{1} b}{a}\right)\left(t_{f}^{d}-t\right)^{q_{1}-2}+\left(\frac{c_{2} c}{a}-\frac{c_{2} q_{2} b}{a}\right)\left(t_{f}^{d}-t\right)^{q_{2}-2}\right. \\
& \left.+\beta \operatorname{sgn}\left(s_{\text {ISM }}\right)\right)=\frac{\dot{V} \cos (\lambda-\gamma)}{g(z)}-V^{2} \frac{\sin (\lambda-\gamma)}{R} \\
& -\frac{\left(\left(c_{1} c / a-c_{1} q_{1} b / a\right)\left(t_{f}^{d}-t\right)^{q_{1}-2}+\left(c_{2} c / a-c_{2} q_{2} b / a\right)\left(t_{f}^{d}-t\right)^{q_{2}-2}+\beta \operatorname{sgn}\left(s_{\text {ISM }}\right)\right)}{g(z)}, \quad \forall t_{0} \leq t \leq t_{f}^{d}-\varepsilon .
\end{aligned}
$$

From (68), we have

$$
\begin{aligned}
|\bar{u}| \leq & \left|\frac{\dot{V} \cos (\lambda-\gamma)}{g(z)}\right|+\frac{\left|\left(\left(c_{1} c / a-c_{1} q_{1} b / a\right)\left(t_{f}^{d}-t\right)^{q_{1}-2}+\left(c_{2} c / a-c_{2} q_{2} b / a\right)\left(t_{f}^{d}-t\right)^{q_{2}-2}+\beta \operatorname{sgn}\left(s_{\text {ISM }}\right)\right)\right|}{|g(z)|} \\
& +\left|V^{2} \frac{\sin (\lambda-\gamma)}{R}\right|, \quad \forall t_{0} \leq t \leq t_{f}^{d}-\varepsilon .
\end{aligned}
$$

$$
\begin{aligned}
|\bar{u}| \leq & \left|\frac{\dot{V} \cos (\lambda-\gamma)}{\bar{\theta}}\right|+\frac{\left|\left(c_{1} c / a-c_{1} q_{1} b / a\right)\left(t_{f}^{d}-t\right)^{q_{1}-2}+\left(c_{2} c / a-c_{2} q_{2} b / a\right)\left(t_{f}^{d}-t\right)^{q_{2}-2}+\beta \operatorname{sgn}\left(s_{\text {ISM }}\right)\right|}{|\bar{\theta}|} \\
& +\left|\frac{V^{2} \sin (\lambda-\gamma)\left(t_{f}^{d}-t_{0}\right)}{R_{0} \cdot\left(t_{f}^{d}-t\right)}\right| \\
\leq & \frac{\left(|\dot{V} \cos (\lambda-\gamma)|+\left|\left(c_{1} c / a-c_{1} q_{1} b / a\right)\right|\left(t_{f}^{d}-t\right)^{q_{1}-2}+\left|c_{2} c / a-c_{2} q_{2} b / a\right|\left(t_{f}^{d}-t_{0}\right)^{q_{2}-2}+\beta\right)}{|\bar{\theta}|} \\
& +\frac{\left|V^{2} \sin (\lambda-\gamma)\left(t_{f}^{d}-t_{0}\right) / R_{0}\right|}{|\varepsilon|}, \quad \forall t_{0} \leq t \leq t_{f}^{d}-\varepsilon .
\end{aligned}
$$


Since $\bar{\theta}>0, \varepsilon>0, q_{1} \geq 2$, and $q_{2} \geq 2$, it is clear that $\bar{u}$ is bounded when $t_{0} \leq t \leq t_{f}^{d}-\varepsilon$. Thus, if the maximum available acceleration $u_{\max }$ is large enough, then condition (66) can be satisfied even if $\varepsilon$ is very small. Since condition (66) can be satisfied, we can know that

$$
\begin{array}{r}
u=\bar{u}=-g^{-1}(z) \\
\cdot\left(f(z)+\frac{b\left(t_{f}^{d}-t\right) z_{2}+c z_{1}}{a\left(t_{f}^{d}-t\right)^{2}}+\beta \operatorname{sgn}\left(s_{\text {ISM }}\right)\right), \\
\forall t_{0} \leq t \leq t_{f}^{d}-\varepsilon .
\end{array}
$$

That is, the guidance law (17) is valid when $t_{0} \leq t \leq t_{f}^{d}-\varepsilon$. Thus the mathematical derivations from (12) to (61) are still valid when $t_{0} \leq t \leq t_{f}^{d}-\varepsilon$. From (37), it is clear that (64) is satisfied. Substituting $t=t_{f}^{d}-\varepsilon$ into (45) yields

$$
R\left(t_{f}^{d}-\varepsilon\right)=V_{\min } \varepsilon+c_{1} \varepsilon^{q_{1}}+c_{2} \varepsilon^{q_{2}} .
$$

From (72), it can be known that condition (65) can be satisfied if $\varepsilon$ is small enough.

In short, for the given small $\varepsilon$ and $R_{\text {set }}$, (64), (65), and (66) can be satisfied simultaneously if $u_{\max }$ is large enough and bounded. Actually, from the simulation result in Section 5 of this paper, it can be known that the modified guidance law (63) can guarantee (64), (65), and (66) are satisfied simultaneously in the case that $R_{\text {set }}=0.1 \mathrm{~m}, \varepsilon=10^{-3} \mathrm{~s}$, and $u_{\max }=100 \mathrm{~m} / \mathrm{s}^{2}$ (from the results in [8-13, 18-20], it can be known that $100 \mathrm{~m} / \mathrm{s}^{2}$ is a reasonable maximum available acceleration for missile; and the objective of ITCG can be accomplished when $R_{\text {set }}=0.1 \mathrm{~m}$ and $\varepsilon=10^{-3} \mathrm{~s}$ ).

3.3. The Permissible Set of the Desired Impact Times. In this section, the permissible set of the desired impact times is discussed. From the above Theorems 1 and 4, the desired impact time and the guidance parameters must satisfy

$$
\begin{aligned}
t_{0} & +\frac{R_{0} q_{\max }}{-\dot{R}_{0}-\left(1-q_{\max }\right) V_{\min }}<t_{f}^{d} \\
& <t_{0}+\frac{R_{0} q_{\min }}{-\dot{R}_{0}-\left(1-q_{\min }\right) V_{\min }}, \quad q_{\max }>q_{\min } \geq 2,
\end{aligned}
$$

where $q_{\max }$ is the maximum value of $q_{1}$ and $q_{2}$ and $q_{\min }$ is the minimum value of $q_{1}$ and $q_{2}$.

From (73), the bound of $t_{f}^{d}$ can be defined as

$$
\xi=t_{0}+\frac{R_{0} q}{-\dot{R}_{0}-(1-q) V_{\min }}, \quad q \geq 2,
$$

where $q$ is variable. If $q=q_{\max }, \xi$ is the lower bound. If $q=q_{\text {min }}, \xi$ is the upper bound, taking the following partial differential operation as

$$
\frac{\partial(\xi)}{\partial q}=\frac{-R_{0}\left(\dot{R}_{0}+V_{\min }\right)}{\left(-\dot{R}_{0}-(1-q) V_{\min }\right)^{2}}, \quad q \geq 2 .
$$

Theorems 1 and 4 need the following condition:

$$
\left|\frac{\dot{R}_{0}}{V_{\min }}\right|=\left|\frac{V_{0} \cos \left(\lambda_{0}-\gamma_{0}\right)}{V_{\min }}\right|<1 .
$$

Combining (75) and (76) yields

$$
\frac{\partial(\xi)}{\partial q}<0, \quad q \geq 2 .
$$

From (75), we know that $\xi$ reduces monotonically with increasing $q$. Then, we get the following.

(a) The lower bound of the permissible set of the desired impact times $t_{f}^{d}$ is $t_{f \text { min }}^{d}$, which is described as

$$
t_{f \min }^{d}=t_{0}+\frac{R_{0}}{V_{\min }} .
$$

If $q_{\max } \rightarrow \infty$, the lower bound can be achieved.

(b) The upper bound of the permissible set of the desired impact times $t_{f}^{d}$ is $t_{f \max }^{d}$, which is described as

$$
t_{f \max }^{d}=t_{0}+\frac{2 R_{0}}{\left(V_{\min }-\dot{R}_{0}\right)} .
$$

If $q_{\text {min }}=2$, we can get the upper bound.

From (a) and (b), the permissible set of the desired impact times $t_{f}^{d}$ can be given as

$$
F=\left(t_{f \min }^{d}, t_{f \max }^{d}\right]
$$

If we select $t_{f}^{d} \in F$ and assume that $\left(t_{f}^{d}-t_{0}\right) V_{\min }-R_{0}>0$, to meet condition (73), the permissible sets of $q_{\max }$ and $q_{\min }$ can be described as

$$
\begin{array}{r}
q_{\max } \in\left(\frac{\left(t_{f}^{d}-t_{0}\right)\left(V_{\min }+\dot{R}_{0}\right)}{\left(\left(t_{f}^{d}-t_{0}\right) V_{\min }-R_{0}\right)}, \infty\right) \cap\left(q_{\min }, \infty\right), \\
q_{\min } \in[2, \infty) .
\end{array}
$$

Because $q_{\max }$ and $q_{\min }$ are the solutions to the equation $a q^{2}-$ $(a+b) q+c=0$, the guidance parameters can be obtained as

$$
\begin{aligned}
& a=1, \\
& b=q_{\max }+q_{\min }-1, \\
& c=q_{\max } q_{\min } .
\end{aligned}
$$

\section{Salvo Attack}

In this section, an algorithm will be designed based on the proposed guidance law to realize the salvo attack. Consider $n$ missiles $M_{i}(i=1, \ldots, n)$ engaged in a salvo attack against a stationary target as shown in Figure 2. $\lambda_{i}$ denotes the LOS angle, $R_{i}$ denotes the relative distance between the missile $M_{i}$ and the target, $\gamma_{i}$ denotes the heading angle, $a_{M i}$ denotes the missile acceleration, and $V_{i}$ denotes the missile velocity. 
for each missile $M_{i}, i=1,2, \ldots, n$ do

Compute the permissible set $F_{i}=\left(t_{f_{i} \min }^{d}, t_{f_{i} \max }^{d}\right]$ from (83).

end for

Find the intersection set $H=\cap_{i=1}^{n} F_{i}$.

Select a $t_{f}^{d} \in H$.

for each missile $M_{i}, i=1,2, \ldots, n$ do

Select $q_{i \max }$ and $q_{i \min }$ from (84) and obtain the

parameters $a_{i}, b_{i}$ and $c_{i}$ from (85).

end for

for each time step do

for each missile $M_{i}, i=1,2, \ldots, n$ do

Use $a_{i}, b_{i}$ and $c_{i}$ to generate the guidance input $u_{i}$ of (18).

end for

end for

Algorithm 1: Salvo attack algorithm.

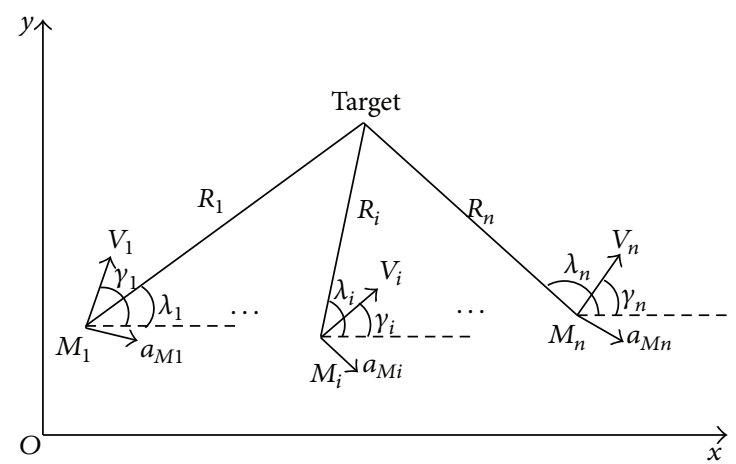

FIGURE 2: Missile-target relative motion relationship.

The permissible set of the desired impact times $t_{f}^{d}$ for missile $M_{i}$ is $F_{i}=\left(t_{f_{i} \min }^{d}, t_{f_{i} \max }^{d}\right.$ ), and the intersection set can be described as $H=\cap_{i=1}^{n} F_{i}$. It is assumed that $H$ is not a null set. Each missile can utilize the guidance law (17) to achieve the desired impact time at each time step. Inspired by the salvo attack strategy introduced in [24], the detailed algorithm is given in Algorithm 1.

\section{Simulation}

In this section, to illustrate the effectiveness of the proposed guidance law, the mathematical simulation is presented. To remove the chattering, $\operatorname{sgn}(x)$ is replaced by the sigmoid function given as [20]

$$
\operatorname{sgmf}(x)=2\left(\frac{1}{1+\exp ^{-\alpha x}}-1\right),
$$

where $\alpha$ is selected as 30 . In addition, the maximum limit of the missile acceleration command is selected as $100 \mathrm{~m} / \mathrm{s}^{2}$.

5.1. Performance of the Proposed Guidance Law. This subsection shows the performance of the proposed guidance law. The simulation result for the missile with constant velocity is shown in Case 1 . And the simulation result for the missile with time-varying velocity is provided in Case 2 . For the comparison, the traditional proportional navigation guidance law (PNGL), the impact-time-control guidance law (ITCGL) in [8], and the nonsingular sliding mode guidance law (NSMGL) in [20] are also considered. The PNGL [8] is defined as

$$
a_{\mathrm{PNGL}}=W V \dot{\lambda}
$$

The parameter is chosen as $W=3$. The ITCGL [8] is defined as

$$
\begin{aligned}
& a_{\mathrm{ITCGL}}=H V \dot{\lambda}\left(\frac{3}{2}-\frac{1}{2}\right. \\
&\left.\cdot \sqrt{1+\frac{240 V^{5}}{(H V \dot{\lambda})^{2} R^{3}}\left(t_{f}^{d}-t-\frac{\left(1+(\gamma-\lambda)^{2} / 10\right) R}{V}\right)}\right)
\end{aligned}
$$

where the parameter is chosen as $H=3$. The NSMGL [20] is defined as

$$
a_{\mathrm{NSMGL}}=a_{M}^{\mathrm{eq}}+a_{M}^{M \operatorname{con}}+a_{M}^{\mathrm{sw}},
$$

where

$$
\begin{aligned}
a_{M}^{\mathrm{eq}}= & \frac{V^{2}(2 N-1)}{R} \frac{(\cos \gamma-1)}{\gamma}+\frac{0.5 V^{2}}{R} \gamma \cos \gamma \\
& +V \dot{\lambda}, \\
h(\gamma)= & \begin{cases}\operatorname{sgn}(\gamma) \gamma & \text { if }|\gamma|<\varepsilon_{1} \\
\frac{1-\varepsilon_{1}}{\varepsilon_{1}-\varepsilon_{2}}|\gamma|+\frac{\varepsilon_{1}\left(\varepsilon_{2}-1\right)}{\left(\varepsilon_{2}-\varepsilon_{1}\right)} & \text { if } \varepsilon_{1}<|\gamma|<\varepsilon_{2} \\
1 & \text { otherwise, }\end{cases} \\
a_{M}^{M \operatorname{con}=} & -\frac{h(\gamma)}{\gamma} k s_{N}, \\
a_{M}^{\mathrm{sw}}= & -M(p \operatorname{sgn}(\gamma)+1) \operatorname{sgn}\left(s_{N}\right), \\
s_{N}= & \frac{R}{V}\left(1+\frac{0.5}{2 N-1} \gamma^{2}\right),
\end{aligned}
$$

where the parameters are chosen as $k=50, M=10, p=2$, $\varepsilon_{1}=0.001, \varepsilon_{2}=0.015$, and $N=3$. In this paper, the values of $W, H, k, M, p, \varepsilon_{1}, \varepsilon_{2}$, and $N$ are the same as that in $[8,20]$ and used here to ensure the fairness of comparison.

Case 1 (missile with constant velocity). In this case, we consider that the missile velocity is constant; that is, $\dot{V}=0$. The initial conditions used in Case 1 are listed in Table 1. From Table 1, the permissible set of the desired impact times can be calculated as $F=(26.1008,42.4381]$ by using $(80)$. Choose the desired impact time as $t_{f}^{d}=37 \mathrm{~s} \in F$. The permissible set of $q_{\max }$ and $q_{\min }$ can be calculated from (81) as $q_{\max } \in(2.6137, \infty) \cap\left(q_{\min }, \infty\right)$ and $q_{\min } \in[2, \infty)$. From the permissible sets, $q_{\max }$ and $q_{\min }$ are selected as $q_{\max }=4$ and $q_{\min }=2.5$. Using $q_{\max }$ and $q_{\min }$, the guidance parameters $a, b$, and $c$ can be obtained from (82) as $a=1, b=5.5$, and $c=10$. 
TABLE 1: Initial condition for Cases 1 and 2.

\begin{tabular}{lcc}
\hline Parameters & $\begin{array}{c}\text { Case 1 (constant } \\
\text { velocity) }\end{array}$ & $\begin{array}{c}\text { Case 2 (varying } \\
\text { velocity) }\end{array}$ \\
\hline Initial missile position & $(-10000,-3000) \mathrm{m}$ \\
Initial missile velocity $V_{0}$ & \multicolumn{2}{c}{$400 \mathrm{~m} / \mathrm{s}$} \\
Initial missile heading & $-60 \mathrm{deg}$ \\
angle $\gamma_{0}$ & $(0,0) \mathrm{m}$ \\
Target position & $37 \mathrm{~s}$ \\
Desired impact time $t_{f}^{d}$ & \multicolumn{3}{c}{$400 \mathrm{~kg}$} \\
Missile mass $m$ & - & $0.039 \mathrm{~m}^{2}$ \\
Reference area $S_{M}$ & - & \\
Air density $\rho$ & $400 \mathrm{~m} / \mathrm{s}$ & $350 \mathrm{~m} / \mathrm{s}$ \\
Minimum speed $V_{\min }$ & \multicolumn{2}{c}{} \\
\hline
\end{tabular}

TABle 2: Performance of guidance laws in Section 5.1.

\begin{tabular}{lccc}
\hline Case & Guidance law & $t_{f}-t_{f}^{d}(\mathrm{~s})$ & Miss distance $(\mathrm{m})$ \\
\hline \multirow{4}{*}{1} & Proposed law & $1.24 \times 10^{-4}$ & 0.07 \\
& NSMGL & $1.45 \times 10^{-4}$ & 0.05 \\
& ITCGL & $3.12 \times 10^{-2}$ & 0.33 \\
& PNGL & -6.39 & 0.03 \\
\hline \multirow{4}{*}{2} & Proposed law & $5.15 \times 10^{-4}$ & 0.15 \\
& NSMGL & 0.57 & 0.06 \\
& ITCGL & 0.49 & 0.47 \\
& PNGL & -3.095 & 0.09 \\
\hline
\end{tabular}

The simulation results of Case 1 are shown in Figures 3(a), 3(b), 3(c), and 3(d) and Table 2, respectively. From Figures 3(a) and 3(b) and Table 2, it can be seen that the proposed law, NSMGL, and ITCGL all can guarantee that the impact time errors are less than $4 \times 10^{-2} \mathrm{~s}$ and the miss distances are less than $1 \mathrm{~m}$, which means that the impact time constraint can be satisfied by using these laws when the missile velocity is constant. The PNGL makes the missile have a large impact time error $-6.39 \mathrm{~s}$, which means that the mission of impact time constraint cannot be accomplished under PNGL. Moreover, in order to control the impact time, it can be seen from Figure 3(c) that the proposed law, NSMGL, and ITCGL employ more control energy compared to PNGL.

Case 2 (missile with time-varying velocity). In this case, we consider that the missile velocity is varying. The aerodynamic coefficients are given by

$$
C_{x}= \begin{cases}-0.37 & t<6 \\ -0.112 & t \geq 6 .\end{cases}
$$

The initial conditions used in Case 1 are listed in Table 1. From Table 1, the permissible set of the desired impact times can be calculated as $F=(29.8294,47.2385]$ by using $(80)$. Choose the desired impact time as $t_{f}^{d}=37 \mathrm{~s} \in F$. Then, the permissible set of $q_{\max }$ and $q_{\min }$ can be calculated from (81) as $q_{\max } \in(3.8033, \infty) \cap\left(q_{\min }, \infty\right)$ and $q_{\max } \in[2, \infty)$. From the permissible sets, $q_{\max }$ and $q_{\min }$ are selected as $q_{\max }=4$ and $q_{\text {min }}=2.5$. Using $q_{\max }$ and $q_{\text {min }}$, the guidance parameters $a, b$, and $c$ can be obtained from (82) as $a=1, b=5.5$, and $c=10$.

The simulation results of Case 2 are shown in Figures 4(a), 4(b), 4(c), and 4(d) and Table 2, respectively. From Figures 4(a) and 4(b) and Table 2, it can be seen that the proposed law can guarantee that the impact time error is only $6 \times 10^{-4} \mathrm{~s}$ and the miss distance is $0.2 \mathrm{~m}$, which means that the impact time constraint (37 s) can be satisfied by using the proposed law. However, for NSMGL and ITCGL, the impact time errors are greater than $0.48 \mathrm{~s}$. As mentioned before, this is because the NSMGL and ITCGL are designed under the assumption that the missile velocity is constant. Compared with the impacttime-control guidance laws based on the assumption that the missile velocity is constant, the proposed law can achieve smaller impact time errors when the velocity is varying.

5.2. Application of Proposed Guidance Law to Salvo Attack Scenario. This subsection is performed with the proposed guidance law for a salvo attack. The air density is $1.293 \mathrm{~kg} / \mathrm{m}^{3}$. The aerodynamic coefficients for each missile are given by

$$
\begin{aligned}
& \text { Missile 1: } C_{x}= \begin{cases}-0.37 & t<6 \\
-0.112 & t \geq 6\end{cases} \\
& \text { Missile 2: } C_{x}= \begin{cases}-0.47 & t<10 \\
-0.325 & t \geq 10\end{cases} \\
& \text { Missile 3: } C_{x}= \begin{cases}-0.57 & t<10 \\
-0.5 & t \geq 10\end{cases}
\end{aligned}
$$

The initial conditions used in this subsection are listed in Table 3 .

From Table 3, the permissible sets of the desired impact times for each missile can be calculated as

$$
\begin{aligned}
& F_{1}=(29.8294,47.2385], \\
& F_{2}=(24.9885,57.3847], \\
& F_{3}=(20.6552,72.9195] .
\end{aligned}
$$

Choose the desired impact time as $t_{f}^{d}=37 \mathrm{~s} \in F_{1} \cap F_{2} \cap F_{3}$. Then, the permissible set of $q_{\max }$ and $q_{\min }$ can be calculated from (81) as

$$
\begin{array}{ll}
q_{1 \max } \in(3.8033, \infty) \cap\left(q_{1 \min }, \infty\right), & q_{1 \min } \in[2, \infty), \\
q_{2 \max } \in(3.4780, \infty) \cap\left(q_{2 \min }, \infty\right), & q_{2 \min } \in[2, \infty), \\
q_{3 \max } \in(3.2450, \infty) \cap\left(q_{3 \min }, \infty\right), & q_{3 \min } \in[2, \infty) .
\end{array}
$$

From the permissible sets, we select that $q_{1 \max }=q_{2 \max }=$ $q_{3 \max }=4$ and $q_{1 \min }=q_{2 \min }=q_{3 \min }=2.5$. Then, the guidance parameters can be obtained from (82) as

$$
\begin{aligned}
& a_{1}=a_{2}=a_{3}=1, \\
& b_{1}=b_{2}=b_{3}=5.5, \\
& c_{1}=c_{2}=c_{3}=10 .
\end{aligned}
$$


TABLE 3: Initial conditions for salvo attack.

\begin{tabular}{lccccccc}
\hline Object & $x_{0} / \mathrm{m}$ & $y_{0} / \mathrm{m}$ & $\gamma_{0} /(\mathrm{deg})$ & $V_{0} /(\mathrm{m} / \mathrm{s})$ & $V_{\min } /(\mathrm{m} / \mathrm{s})$ & \multicolumn{1}{c}{$S_{a s s} /(\mathrm{kg})$} & 0 \\
\hline Target & 0 & 0 & 0 & 0 & 0 & 350 & 400 \\
Missile 1 & -10000 & -3000 & -60 & 400 & 410 & 330 & 395 \\
Missile 2 & -2000 & -8000 & -20 & 420 & 310 & 0.039 \\
Missile 3 & -5000 & 4000 & 70 & 0.040 \\
\hline
\end{tabular}

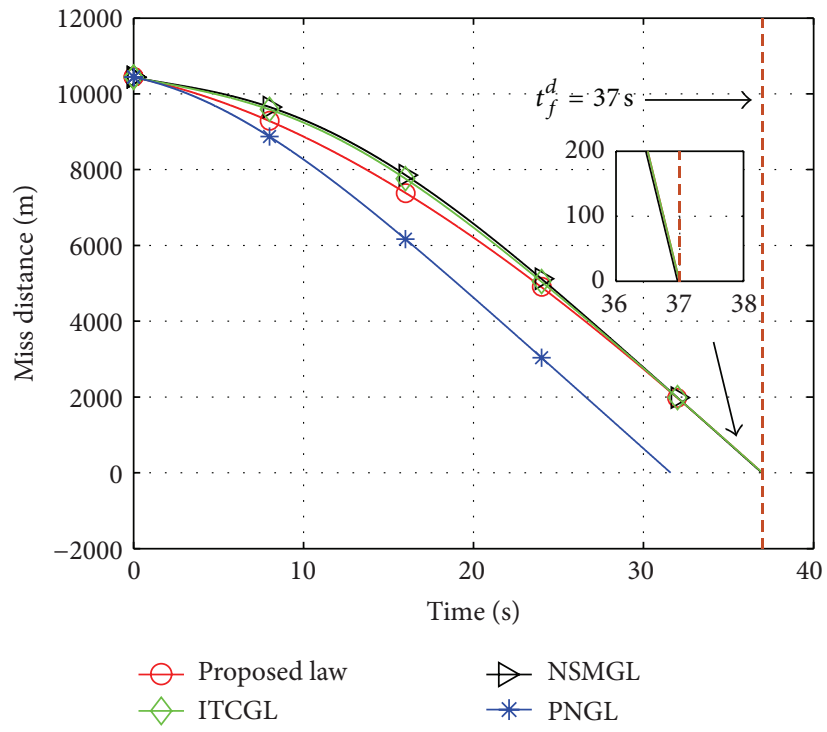

(a) Miss distance $R$

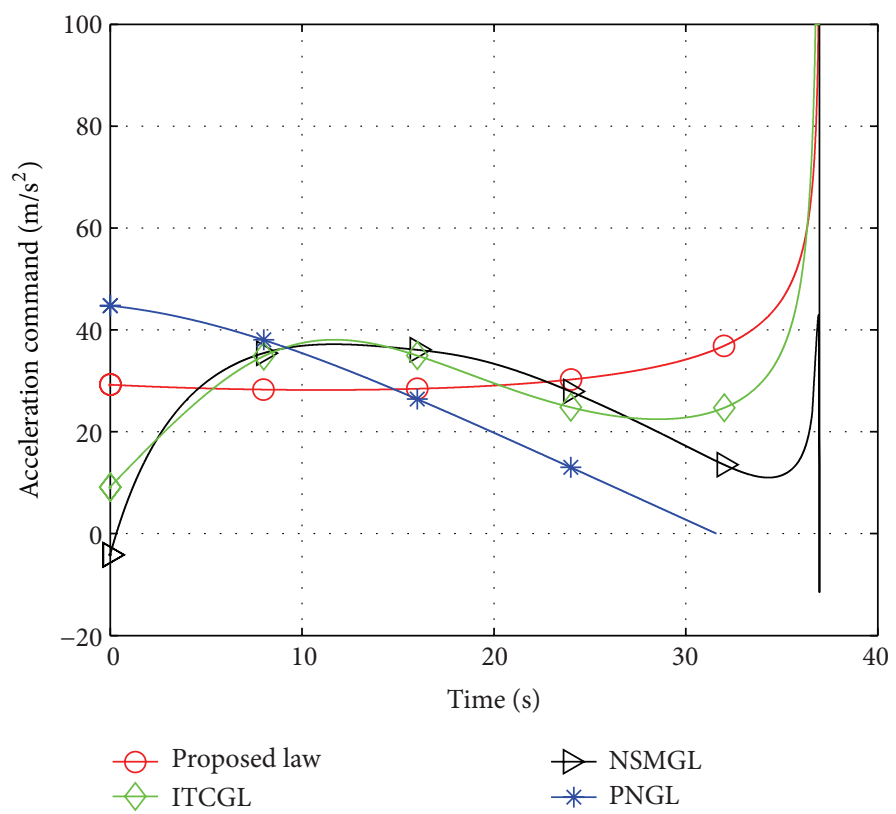

(c) Acceleration command

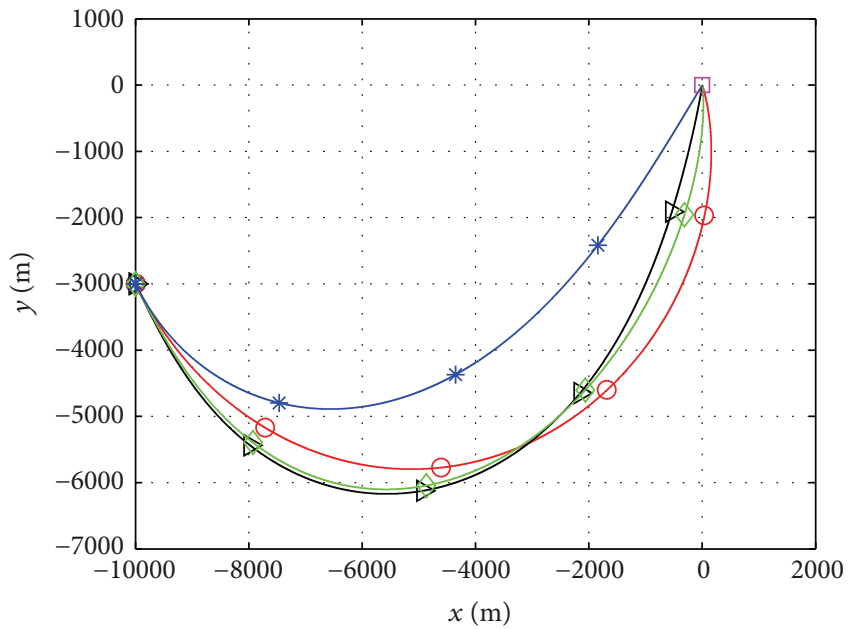

$\bigcirc$ Proposed law

$\diamond$ ITCGL

$\gg$ NSMGL

$\square$ Target

(b) Flight trajectory

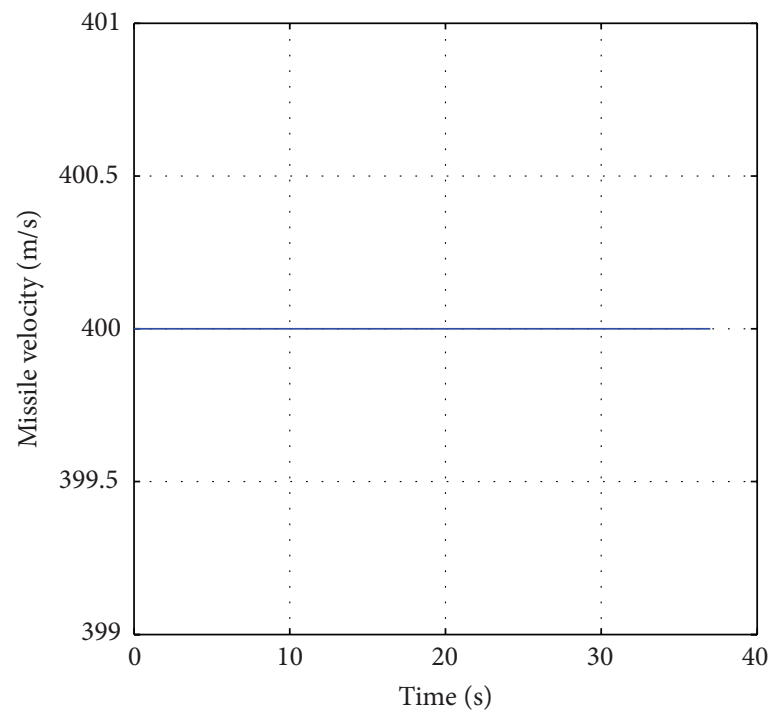

Figure 3: Responses in Case 1 (constant velocity). 


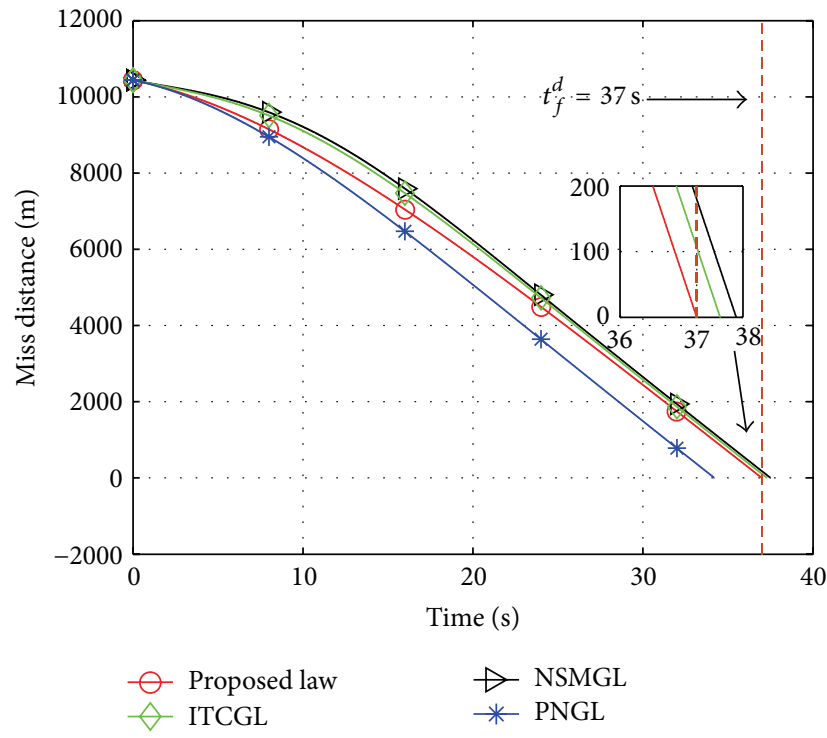

(a) Miss distance $R$

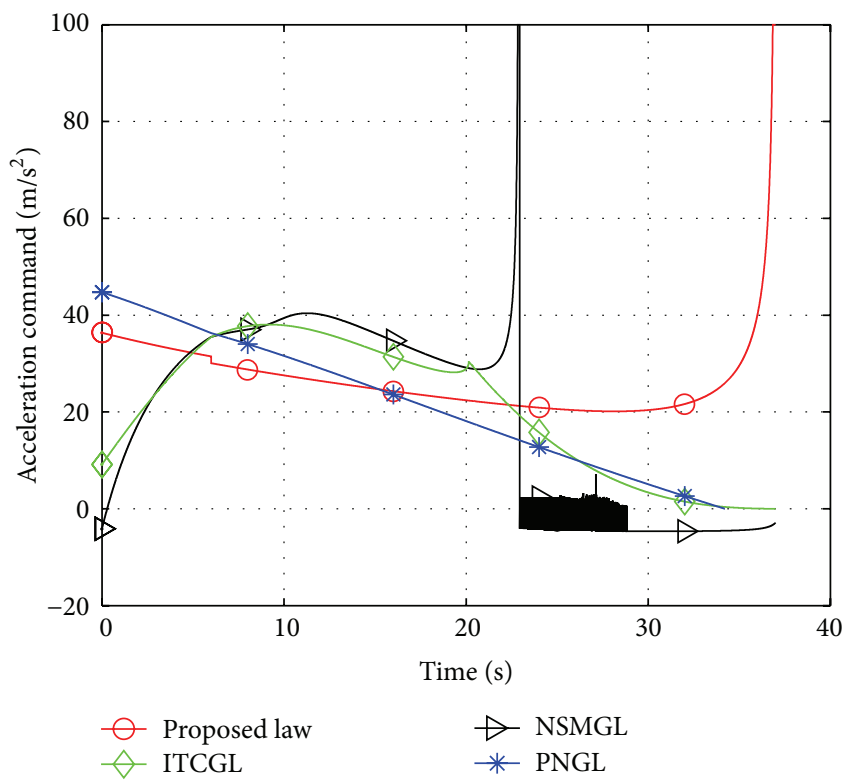

(c) Acceleration command

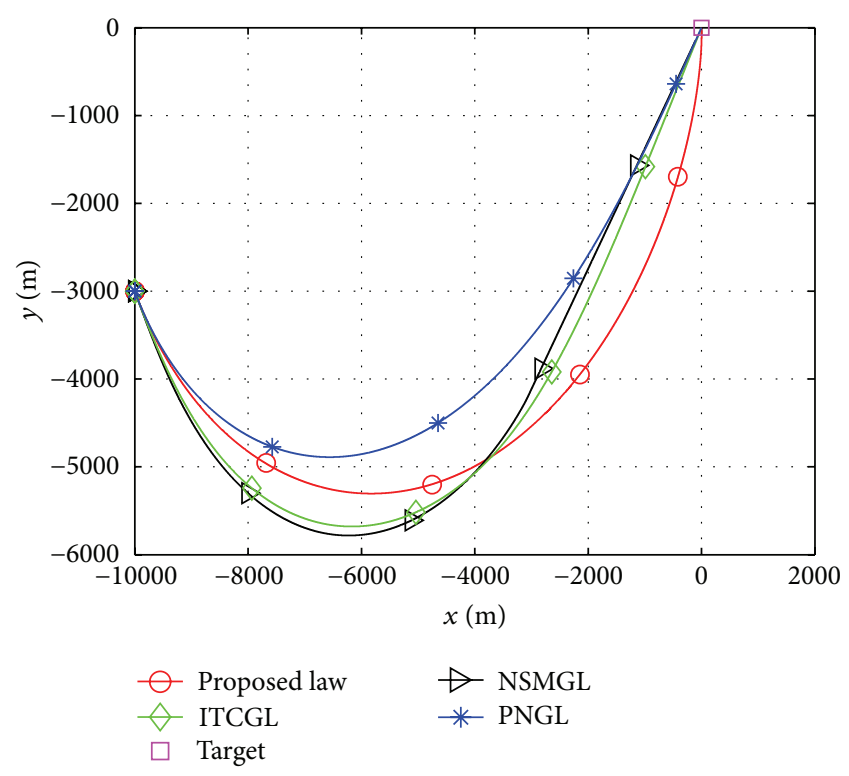

(b) Flight trajectory

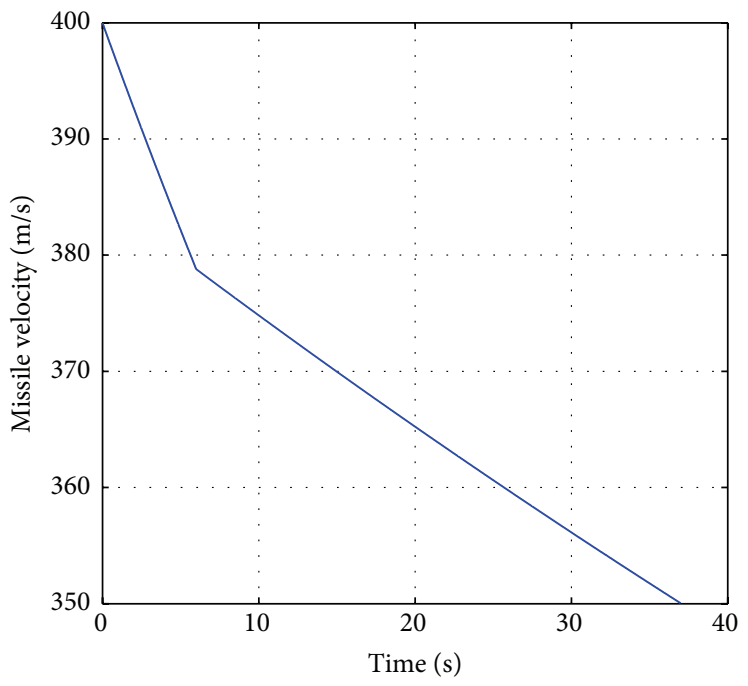

(d) Missile velocity

FIgURE 4: Responses in Case 2 (time-varying velocity).

TABLe 4: Performance of guidance law in Section 5.2.

\begin{tabular}{lcc}
\hline Object & $t_{f}-t_{f}^{d}(\mathrm{~s})$ & Miss distance $(\mathrm{m})$ \\
\hline Missile 1 & $3.13 \times 10^{-4}$ & 0.15 \\
Missile 2 & $1.15 \times 10^{-4}$ & 0.45 \\
Missile 3 & $0.89 \times 10^{-4}$ & 0.31 \\
\hline
\end{tabular}

The simulation results are shown in Figures 4(a), 4(b), 4(c), and 4(d) and Table 4, respectively. From Figures 5(a), 5(b), 5(c), and 5(d) and Table 4, it is clear that the proposed law can guarantee the miss distances are less than $0.5 \mathrm{~m}$, and the impact time errors are less than $4 \times 10^{-4} \mathrm{~s}$, which means that the missiles can accomplish salvo attack even if the missile velocities are time-varying.

\section{Conclusions}

In this paper, a novel ITCG law has been proposed for the homing missile with time-varying velocity. The main contribution here is that the proposed ITCG law relaxed the constant velocity assumption which is needed for the existing ITCG laws. Since most missiles have time-varying velocity, the proposed method is more feasible than the existing ITCG 


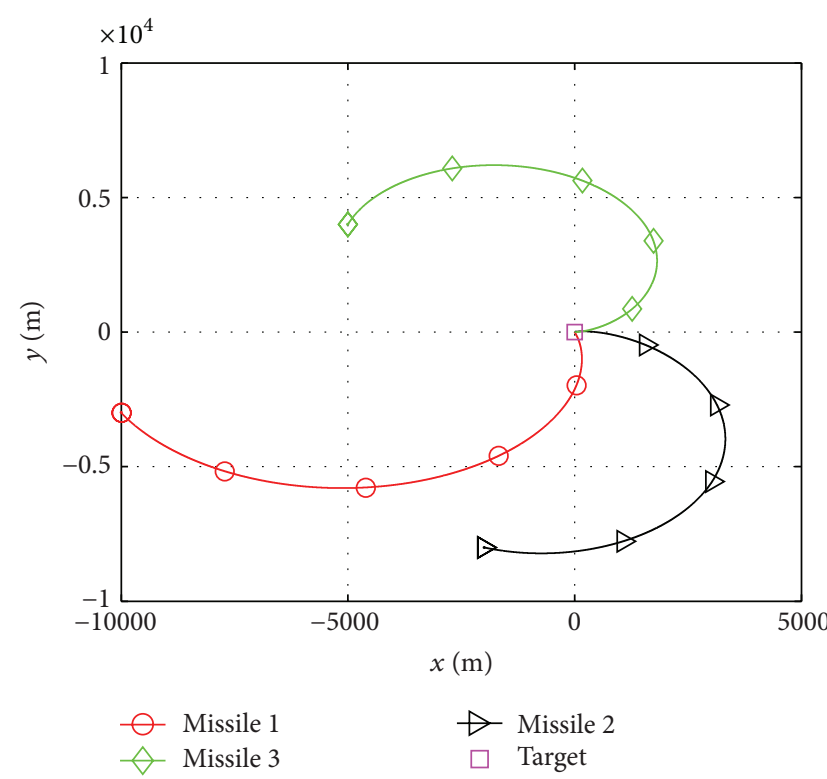

(a) Flight trajectory

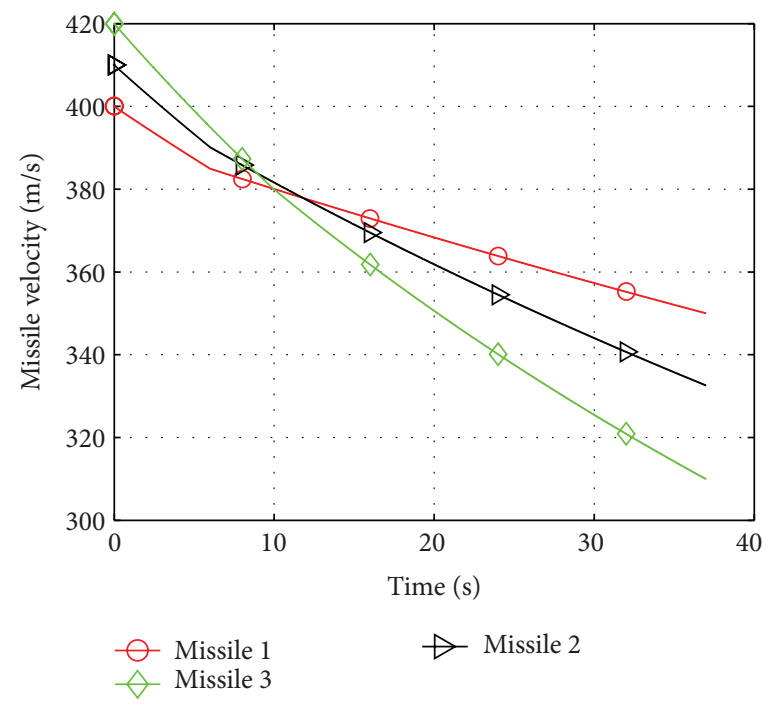

(c) Missile velocity

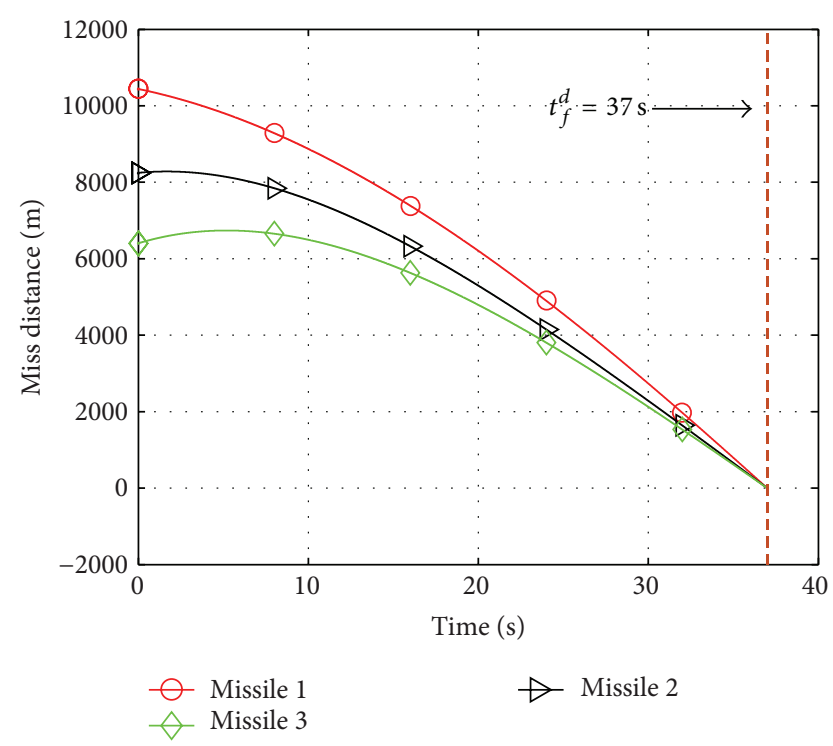

(b) Miss distance $R$

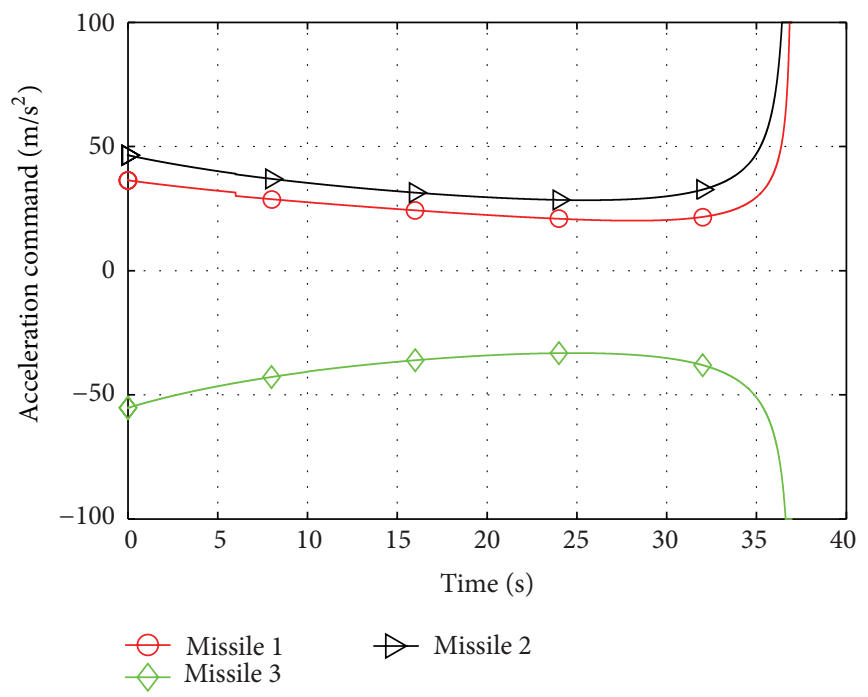

(d) Acceleration command

FIgURE 5: Responses in the salvo attack scenario.

laws in engineering. In addition, the proposed law also exhibited one attractive feature. The proposed guidance law was derived based on the nonlinear engagement dynamic rather than the linearized-engagement-dynamics used in many traditional ITCG laws. A salvo attack algorithm has been developed based on the proposed ITCG law. The theoretical derivations and simulation results all demonstrated that the proposed guidance law achieved a better performance than the existing ITCG laws when the missile velocity is timevarying and that the proposed salvo attack algorithm worked well.

\section{Competing Interests}

The authors declare that there is no conflict of interests regarding the publication of this paper.

\section{Acknowledgments}

This work is supported by the National Natural Science Foundation of China (61304238), the National High-Tech R\&D Program of China (2012AA120602, 2015AAxxx7033, and 2015AAxxx1008), and the Chinese Aerospace Supported Fund (2015-HT-XGD).

\section{References}

[1] S. N. Ghawghawe and D. Ghose, "Pure proportional navigation against time-varying target maneuvers," IEEE Transaction on Control Systems Technology, vol. 22, no. 4, pp. 589-594, 1999.

[2] M. Guelman, "The closed-form solution of true proportional navigation," IEEE Transaction on Aerospace and Electronic Systems, vol. AES-12, no. 4, pp. 472-482, 1976. 
[3] P.-J. Yuan and J.-S. Chern, "Solutions of true proportional navigation for maneuvering and nonmaneuvering targets," Journal of Guidance, Control, and Dynamics, vol. 15, no. 1, pp. 268-271, 1992.

[4] C.-D. Yang, F.-B. Hsiao, and F.-B. Yeh, "Generalized guidance law for homing missiles," IEEE Transactions on Aerospace and Electronic Systems, vol. 25, no. 2, pp. 197-212, 1989.

[5] R. H. Chen, J. L. Speyer, and D. Lianos, "Terminal and boost phase intercept of ballistic missile defense," in Proceedings of the AIAA Guidance, Navigation and Control Conference and Exhibit, Honolulu, Hawaii, USA, August 2008.

[6] S. Fucci and P. Zuzolo, "Avionics and ecm system integration on military aircraft," Journal of Aircraft, vol. 8, no. 5, pp. 388-391, 1971.

[7] C.-K. Ryoo, I. Whang, and M.-J. Tahk, "3-D evasive maneuver policy for anti-Ship missiles against close-in weapon systems," in Proceedings of the AIAA Guidance, Navigation, and control conference and Exhibit, Austin, Tex, USA, 2003.

[8] I.-S. Jeon, J.-I. Lee, and M.-J. Tahk, "Impact-time-control guidance law for anti-ship missiles," IEEE Transactions on Control Systems Technology, vol. 14, no. 2, pp. 260-266, 2006.

[9] S. Zhao and R. Zhou, "Cooperative guidance for multimissile salvo attack," Chinese Journal of Aeronautics, vol. 21, no. 6, pp. 533-539, 2008.

[10] Y. Zhang, G. Ma, and A. Liu, "Guidance law with impact time and impact angle constraints," Chinese Journal of Aeronautics, vol. 26 , no. 4, pp. 960-966, 2013.

[11] J.-I. Lee, I.-S. Jeon, and M.-J. Tahk, "Guidance law to control impact time and angle," IEEE Transactions on Aerospace and Electronic Systems, vol. 43, no. 1, pp. 301-310, 2007.

[12] Y. Zhang, X. Wang, and H. Wu, "Impact time control guidance with field-of-view constraint accounting for uncertain system lag," Proceedings of the Institution of Mechanical Engineers, Part G: Journal of Aerospace Engineering, vol. 230, no. 3, pp. 515-529, 2016.

[13] T.-H. Kim, C.-H. Lee, I.-S. Jeon, and M.-J. Tahk, "Augmented polynomial guidance with impact time and angle constraints," IEEE Transactions on Aerospace and Electronic Systems, vol. 49, no. 4, pp. 2806-2817, 2013.

[14] F. Castanos and L. Fridman, "Analysis and design of integral sliding manifolds for systems with unmatched perturbations," IEEE Transactions on Automatic Control, vol. 51, no. 5, pp. 853858, 2006.

[15] J. Y. Hung, W. Gao, and J. C. Hung, "Variable structure control: a survey," IEEE Transactions on Industrial Electronics, vol. 40, no. 1, pp. 2-22, 1993.

[16] K.-S. Kim, Y. Park, and S.-H. Oh, "Designing robust sliding hyperplanes for parametric uncertain systems: a Riccati approach," Automatica, vol. 36, no. 7, pp. 1041-1048, 2000.

[17] J. Wang, S. Li, J. Yang, B. Wu, and Q. Li, "Extended state observer-based sliding mode control for PWM-based DC-DC buck power converter systems with mismatched disturbances," IET Control Theory and Applications, vol. 9, no. 4, pp. 579-586, 2015.

[18] N. Harl and S. N. Balakrishnan, "Impact time and angle guidance with sliding mode control," IEEE Transactions on Control Systems Technology, vol. 20, no. 6, pp. 1436-1449, 2012.

[19] S. R. Kumar and D. Ghose, "Sliding mode control based guidance law with impact time constraints," in Proceedings of the 1st American Control Conference (ACC '13), pp. 5760-5765, IEEE, Washington, DC, USA, June 2013.
[20] D. Cho, H. J. Kim, and M.-J. Tahk, "Nonsingular sliding mode guidance for impact time control," Journal of Guidance, Control, and Dynamics, vol. 39, no. 1, pp. 61-68, 2016.

[21] H. Cho, C. K. Ryoo, and M.-J. Tahk, "Closed-form optimal guidance law for missiles of time-varying velocity," Journal of Guidance, Control, and Dynamics, vol. 19, no. 5, pp. 1017-1022, 1996.

[22] Z. Zhang, S. Li, and S. Luo, "Composite guidance laws based on sliding mode control with impact angle constraint and autopilot lag," Transactions of the Institute of Measurement and Control, vol. 35, no. 6, pp. 764-776, 2013.

[23] Z. Zhang, S. Li, and S. Luo, "Terminal guidance laws of missile based on ISMC and NDOB with impact angle constraint," Aerospace Science and Technology, vol. 31, no. 1, pp. 30-41, 2013.

[24] A. Saleem and A. Ratnoo, "Lyapunov-based guidance law for impact time control and simultaneous arrival," Journal of Guidance, Control, and Dynamics, vol. 39, no. 1, pp. 164-172, 2016. 


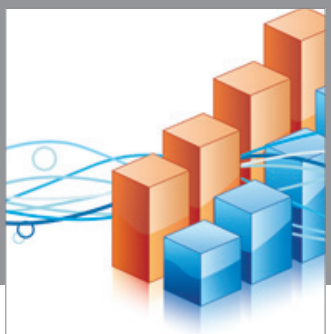

Advances in

Operations Research

vatem alat4

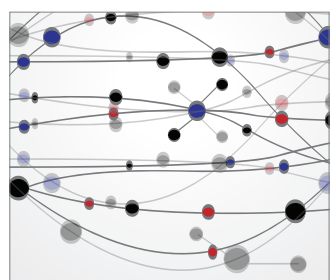

\section{The Scientific} World Journal
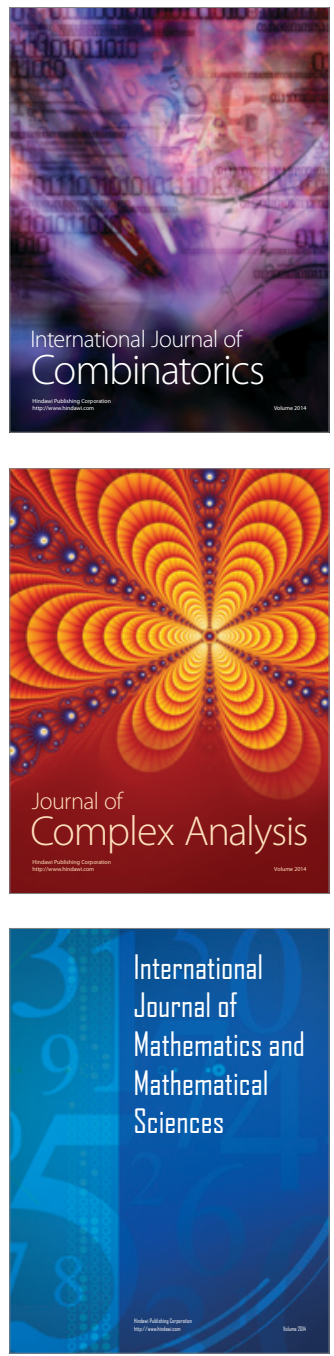
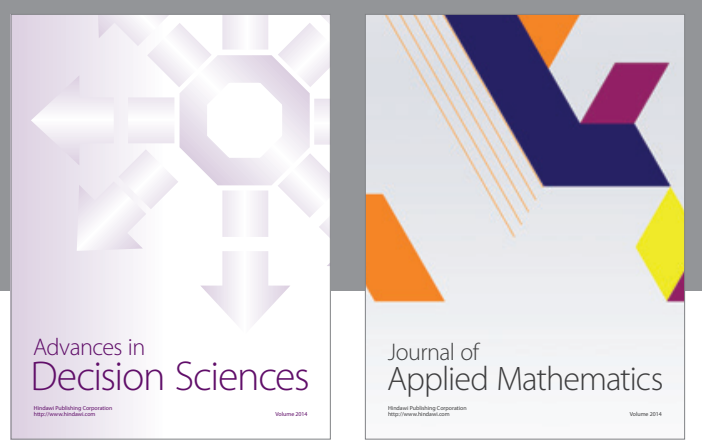

Algebra

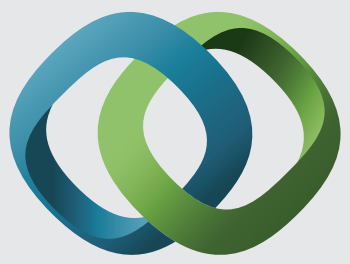

\section{Hindawi}

Submit your manuscripts at

http://www.hindawi.com
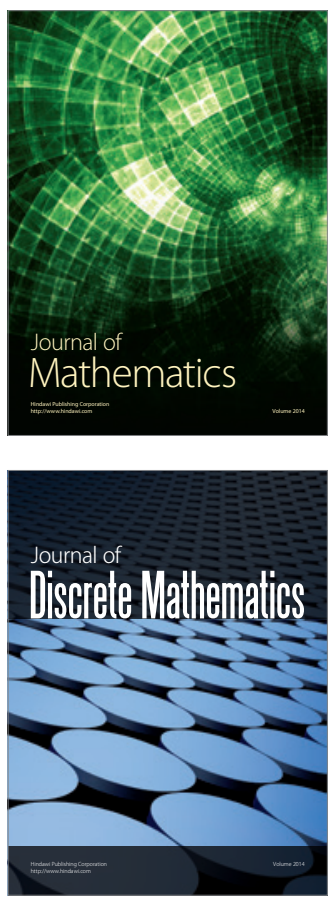

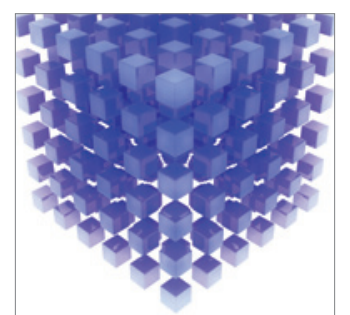

Mathematical Problems in Engineering
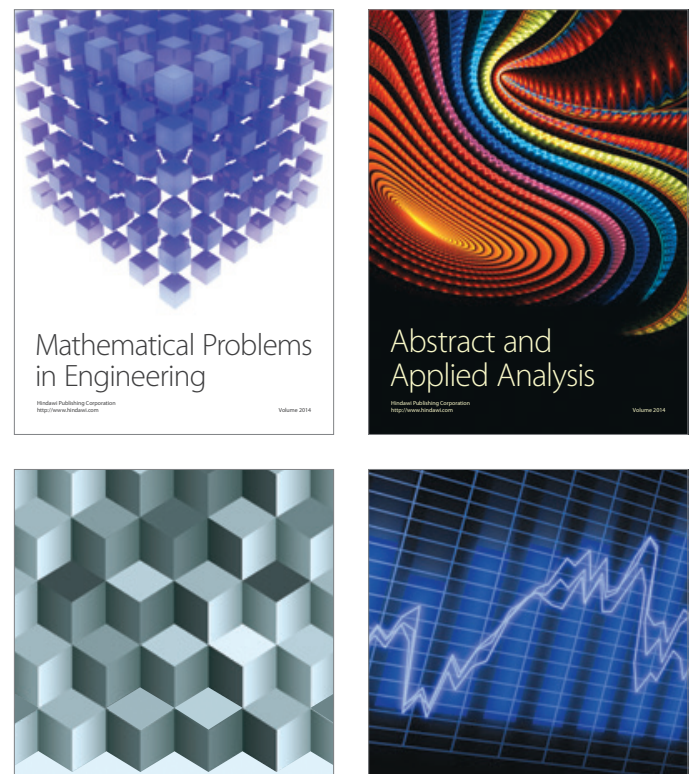

Journal of

Function Spaces

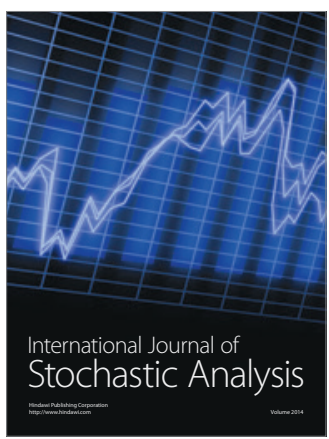

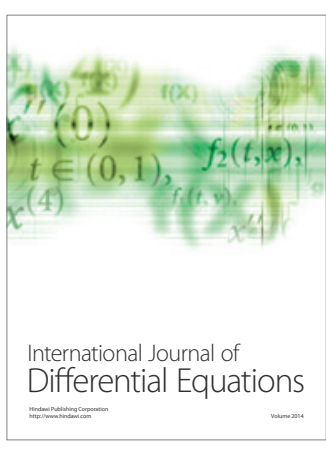
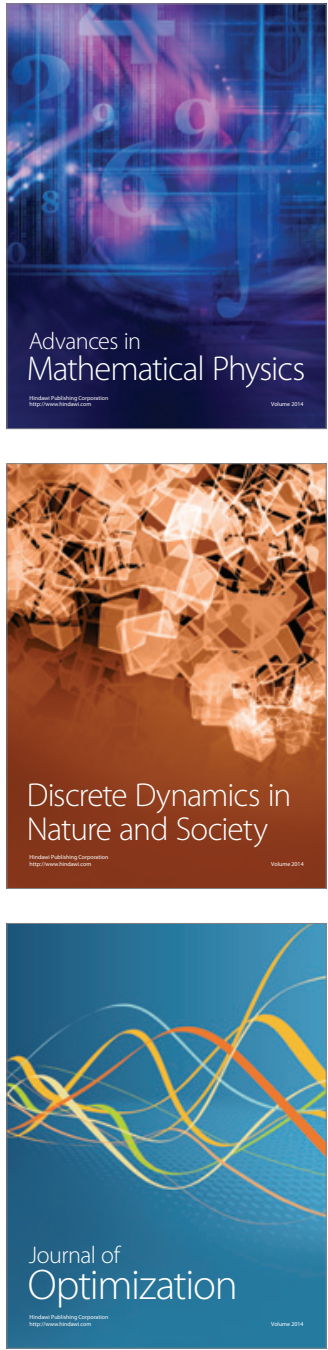